\title{
The roles of MAPKs in disease
}

Michael C Lawrence ${ }^{1}$, Arif Jivan ${ }^{1}$, Chunli Shao ${ }^{1}$, Lingling Duan ${ }^{1}$, Daryl Goad ${ }^{1}$, Elma Zaganjor ${ }^{1}$, Jihan Osborne ${ }^{1}$, Kathleen McGlynn ${ }^{1}$, Steve Stippec ${ }^{1}$, Svetlana Earnest ${ }^{1}$, Wei Chen ${ }^{1}$, Melanie H Cobb ${ }^{1}$

${ }^{1}$ Department of Pharmacology, University of Texas Southwestern Medical Center at Dallas, 6001 Forest Park Road, Dallas, TX 75390-9041, USA

MAP kinases transduce signals that are involved in a multitude of cellular pathways and functions in response to a variety of ligands and cell stimuli. Aberrant or inappropriate functions of MAPKs have now been identified in diseases ranging from cancer to inflammatory disease to obesity and diabetes. In many cell types, the MAPKs ERK1/2 are linked to cell proliferation. ERK1/2 are thought to play a role in some cancers, because mutations in Ras and B-Raf, which can activate the ERK1/2 cascade, are found in many human tumors. Abnormal ERK1/2 signaling has also been found in polycystic kidney disease, and serious developmental disorders such as cardio-facio-cutaneous syndrome arise from mutations in components of the ERK1/2 cascade. ERK1/2 are essential in well-differentiated cells and have been linked to long-term potentiation in neurons and in maintenance of epithelial polarity. Additionally, ERK1/2 are important for insulin gene transcription in pancreatic beta cells, which produce insulin in response to increases in circulating glucose to permit efficient glucose utilization and storage in the organism. Nutrients and hormones that induce or repress insulin secretion activate and/or inhibit ERK1/2 in a manner that reflects the secretory demand on beta cells. Disturbances in this and other regulatory pathways may result in the contribution of ERK1/2 to the etiology of certain human disorders. Keywords: cancer, polycystic kidney disease, docking motifs, Mxi2, insulin gene transcription, PEA-15, CHOP Cell Research (2008) 18:436-442. doi: 10.1038/cr.2008.37; published online 18 March 2008

The aberrant or inappropriate function of mitogen-activated protein kinases (MAPKs) has now been identified in diseases ranging from cancer to inflammatory disease to obesity and diabetes [1-3]. As described in more detail below, MAPKs are ubiquitous elements in signaling pathways that control cell function [4-8]. In this review we present some background on MAPK pathways and then discuss key findings that suggest mechanisms that may link MAPKs to specific diseases. The focus will be on ERK1/2 because ERK2 has long served as the prototype to understand the regulation and function of MAPKs and their cascades.

\section{MAPK cascades}

MAPKs are activated by protein kinase cascades consisting of three or more protein kinases in series: MAPK kinase kinases (MAP3Ks) activate MAPK kinases (MAP2Ks) by dual phosphorylation on S/T residues; MAP2Ks then activate MAPKs by dual phosphorylation on $\mathrm{Y}$ and $\mathrm{T}$ residues. MAPKs then phosphorylate target substrates on select S/T

Correspondence: Melanie H Cobb

E-mail: Melanie.Cobb@UTSouthwestern.edu residues typically followed by P. In the ERK1/2 cascade the MAP3K is usually a member of the Raf family. Many diverse MAP3Ks reside upstream of the p38 and the c-Jun N-terminal kinase/stress-activated protein kinase (JNK/ SAPK) MAPK groups, which have generally been associated with responses to cellular stress. Downstream of the activating stimuli, the kinase cascades may themselves be stimulated by combinations of small G proteins, MAP4Ks, scaffolds, or oligmerization of the MAP3K in a pathway. In the ERK1/2 pathway, Ras family members usually bind to Raf proteins leading to their activation [4-8].

Through these cascades, the MAPKs process signals from most ligands and changes in cell state, thus, affecting the majority of cellular responses. Signaling by MAPKs affects specific events such as the activity or localization of individual proteins, transcription of genes, and increased cell cycle entry, and promotes changes that orchestrate complex processes such as embryogenesis and differentiation. These enzymes mediate acute responses to hormones such as changes in membrane permeability, cell motility, and transcription of immediate early genes; homeostatic responses of intermediate duration such as stimulus-induced long term potentiation in neurons; and sequenced programs required for animal development [9- 
12]. In fact, ERK2 is an essential gene. Animals that lack it die early in embryonic development [13]. Furthermore, germline mutations in the ERK1/2 cascade are associated with serious developmental abnormalities such as cardiofacio-cutaneous syndrome [14].

\section{Early studies implicating MAPKs in disease}

Among the earliest suggestions that ERK1/2 activity might contribute to disease was the finding that the ERK1/2 cascade was a downstream target for receptor tyrosine kinases as well as for Ras, which is commonly mutated in human cancers [15-17]. A wealth of studies suggest that ERK $1 / 2$ have an array of actions in different cancers, both in ones in which Ras mutations have been found and ones lacking Ras mutations [1, 18-22]. Many studies suggest a lack of correlation between ERK1/2 activation state and tumor growth. The ability of ERK1/2 to promote epithelial-mesenchymal transition and to facilitate cell migration through effects on cell-matrix contacts is most likely significant even if the sustained activation of the kinases is not detected in tumors [23, 24].

Roles of other MAPKs have been revealed more recently through a combination of drug studies and gene disruption experiments. One of the first identifications of a p38 MAPK was through a search for the target of an anti-inflammatory drug that inhibited tumor necrosis factor-alpha production from human monocytes [25]. Thus, the efficacy of the drug itself provoked a search for this MAPK family member. One of the early studies of the c-Jun N-terminal kinases/stress-activated protein kinases (JNK/SAPKs) was the result of a search for kinases that could phosphorylate and activate the proto-oncogene c-Jun [26]. More recently, mouse studies indicated that loss of JNK1 improved insulin sensitivity and decreased fat deposition, demonstrating that JNKs are involved in obesity and insulin resistance [3]. JNKs are activated by increased circulating long chain fatty acids and can suppress insulin signaling through phosphorylation of insulin receptor substrate 1 (IRS1) [27].

\section{Perturbations in cascade organization and cancer}

The wide expression of MAPKs and their nearly universal involvement in signaling events underscore the capacity of these protein kinases to impact cellular function. The variety of actions elicited by MAPKs is assumed to depend on the tissue-specific expression of targets, differences in their activation kinetics and subcellular localization as well as the context of cell state. These events are believed to account for the ability of very common signal transducers such as the MAPKs to perform with selectivity and specificity to contribute to ligand- and state-dependent responses.
Localization and interactions of MAPKs are strongly influenced by scaffolding proteins [28]. In addition to core cascade components, MAPK, MAP2K, MAP3K, accessory proteins are required to produce ligand/context-appropriate responses. Scaffolds organize the core components to allow them to interact efficiently in multi-protein complexes. Most simply, a scaffold facilitates signaling by increasing the local concentrations of the pathway components; however, scaffolds may also actively participate in the functions of their binding partners. Thus, a scaffold may affect its MAPK by: 1) interacting directly with membrane activators; 2 ) localizing it to sites of action on the membrane and elsewhere in a cell; 3 ) causing allosteric changes to sensitize the MAPK to activation, e.g., by inducing MAPK conformations that are more readily recognized by MAP2Ks or that mimic the active state; 4 ) affecting MAPK substrate accessibility; 5) influencing activation kinetics; 6) regulating inactivation; and 7) restricting responses by preventing irrelevant interactions [28-32].

MAPKs bind outside their active sites to many proteins [33-38]. Three MAPK-binding motifs have been identified in many ERK1/2 binding proteins: the docking or D motif consisting of basic and hydrophobic residues, involved, for example, in binding of MAP2Ks, substrates such as the ternary complex factor Elk-1, and MAP kinase phosphatases (MKPs); the FXF motif, present in some substrates such as Elk-1, nuclear pore proteins, and some scaffolds; and a leucine-rich motif LXLXXXF found in pointed domain transcription factors. D motifs bind to a region called the common docking (CD) site across the C-terminal domain of ERK2 $[39,40]$. These binding motifs are often required for efficient phosphorylation of the substrates that harbor them by ERK1/2 in cells [36, 41-44]. Protein binding to or mutation of these motifs may have an allosteric action on MAPKs. Almost all mutations that have been identified in the ERK1/2 pathway in tumors lie in upstream cascade elements, including receptors, Ras, and B-Raf. However, one mutated form of ERK2 was identified in a squamous cell carcinoma cell line [45]. The residue mutated is in the docking site for $\mathrm{D}$ domains and results in an increase in basal ERK2 activity [46].

\section{Signaling imbalances and the potential role of ERK1/2 in polycystic kidney disease}

Factors that disturb the normal relationship between cyclic nucleotides and ERK1/2 activity may lead to inappropriate actions of these kinases that exacerbate disease. The sensitivity of ERK1/ 2 to stimuli is influenced by cyclic nucleotide concentrations in a manner dependent on the specific cell condition, such as whether a cell is actively dividing, its interactions with neighboring cells, and the 
milieu of hormones, growth factors, and cytokines [47, 48]. MAPKs can have profound effects on gene transcription profiles, leading to under- or over-expression of key proteins, and can contribute to loss of epithelial cells (such as by epithelial-mesenchymal transition) and expansion of the smooth muscle population [49, 50].

Mechanisms integrating inputs from cAMP to ERK1/2 are not fully understood. The clinical relevance of understanding their interactions is most obvious in the change in ERK1/2 regulation by cAMP in polycystic kidney disease (PKD) [51, 52]. PKD is often caused by loss of polycystin 1 or 2 . The consequence is loss of these components from cilia on kidney epithelial cells which results in altered signaling by these cells. Cilia are sensors of growth factors and other signals in many cell types and contain components of the ERK $1 / 2$ cascade [53-55]. Polycystin 2 is a poorly understood nonselective cation channel located in cilia which binds to and is regulated by polycystin 1 . Polycystins are thought to maintain proper intracellular calcium. In normal kidney, ERK1/2 support growth inhibition in response to elevated cAMP. In PKD, ERK1/2 appear to induce proliferation in response to elevated cAMP, which results in the formation of cysts and loss of epithelial polarity $[51,56]$. Inhibition of the ERK1/2 pathway decreases abnormal proliferation. Kidney cells are routinely stimulated by vasopressin which causes fluid reabsorption by increasing cAMP. As a result, kidney cells are continuously experiencing elevated cAMP. Altering intracellular calcium has been shown to change the interactions between cAMP and the ERK1/2 pathway in normal kidney cells in a manner that mimics the aberrant signaling in PKD [51].

\section{Mislocalization of ERK1/2 in disease}

Activation of ERK1/2 has different consequences in different cell compartments. Stimuli will direct ERK1/2 to specified sites of action, so that they may perform functions, for example, on membranes, with cytoskeletal specializations, and/or in the nucleus [57-59]. As much as half of ERK1/2 is bound to cytoplasmic microtubules, where they impact polymerization dynamics [60-62]. ERK1/2 are required for cell motility and are found at adherens junctions and focal adhesions, sites of cell-cell and cell-matrix contact. Nuclear localization of ERK1/2 is essential for some of the phenotypic programs to which they contribute including differentiation, transformation and altered transcription (a few transcription factors can be phosphorylated by ERK $1 / 2$ in the cytoplasm prior to nuclear entry) [63]. In the large majority of resting cells, ERK1/2 are distributed in the cytoplasm and the nucleus [58, 64, 65].

Proteins that alter the subcellular localization of ERK1/2 have the capacity to impact disease. For example, the cyto- plasmic retention of ERK1/2 occurs in a fraction of breast cancer patients and is suggested to favor long-term survival of these patients [66-68]. Expression of Mxi2, a p38 MAPK splice form, increases the concentration of ERK1/2 in the nucleus. Mxi2 is overexpressed in certain renal cancers and its effect on ERK1/2 localization may contribute to disease [69]. PEA-15 is a $15 \mathrm{kDa}$ anti-apoptotic, death effector domain-containing protein originally identified as a protein enriched in astrocytes [70]. A second study identified PEA-15 as PED or protein enriched in diabetes [66]. Its increased expression was widespread in tissues in a panel of patients with type 2 but not type 1 diabetes. Transgenic mice overexpressing PEA-15 exhibit decreased glucose tolerance and develop diabetes on a high fat diet [71]. These animals also display impaired insulin secretion. Cultured pancreatic beta cells overexpressing PEA-15 have a reduced capacity for glucose-stimulated insulin secretion. Based on studies in other systems, PEA-15 is thought not only to promote nuclear export of ERK2 but also to prevent ERK2 nuclear entry by blocking its interaction with nucleoporins $[72,73]$. These studies suggest that the mislocalization of ERK1/2 may contribute to the dysregulation of glucose-sensing in pancreatic beta cells.

\section{Potential roles of ERK1/2 in diabetes}

In pancreatic beta cells, glucose regulates insulin secretion as well as insulin production at transcriptional and translational levels. The same nutrients and hormones that stimulate insulin secretion also increase ERK1/2 activity $[74,75]$. Glucose uptake and metabolism are required for ERK1/2 activation. Depolarization of beta cells with $\mathrm{K}^{+}$or with sulfonylurea antidiabetic drugs also activates ERK1/2, but with kinetics different from glucose $[75,76]$. Calcium entry through voltage-gated calcium channels is essential for maximal ERK activation by a rise in glucose concentration [74, 76-78]. The calcium- and calmodulindependent phosphoprotein phosphatase calcineurin is essential for ERK1/2 activation by glucose, other nutrients, and the anticipatory hormone glucagon-like peptide I (Glp1) [77, 79].

The normal physiological range of glucose concentrations stimulate insulin gene transcription. This stimulatory effect of glucose requires ERK1/2 [11, 80]. Glucose-responsive elements in the insulin gene promoter have been found in the region proximal to the transcription start site. $\mathrm{E}$ and $\mathrm{A}$ elements are the most glucose sensitive and exist in two regions of the insulin gene promoter. Several transcription factors contribute to beta cell differentiation and insulin gene transcription and some of these, e.g., Beta2, PDX-1, and MafA, display tissue restricted expression $[81,82]$. These tissue restricted factors bind to the glucose 
sensitive regions and are responsible for beta cell-specific, glucose-induced insulin gene expression. All three of these factors are in vitro substrates for ERK1/2, and functional changes due to phosphorylation, in particular DNA binding, have been shown for all. Mutations in two of these factors, PDX-1 and Beta2, are associated with maturity onset diabetes of the young (MODY) type 4 and type 6, respectively [82].

Glucose concentrations that remain elevated for prolonged times, more than $24 \mathrm{~h}$, inhibit insulin gene transcription $[83,84]$. The inhibitory effect is also dependent on ERK $1 / 2$ activity [80]. Long term exposure to abnormally high glucose induces expression of CCAAT/enhancerbinding protein beta (C/EBP- $\beta)$. This protein binds to the insulin gene promoter in an ERK1/2-dependent manner and changes the composition of other transcription factors bound to the promoter, contributing to inhibition of insulin gene transcription. The mechanisms by which ERK1/2 control the interactions of the stimulatory and inhibitory transcription factors with promoter DNA have not been completely defined. Taken together, these findings suggest that the impairment in insulin gene transcription that occurs in type II diabetes is due in part to the phosphorylation of factors that inhibit the insulin gene promoter by ERK1/2.

The large amount of insulin produced by beta cells makes them highly susceptible to endoplasmic reticulum (ER) stress [85]. ER stress can lead to beta cell death. The C/EBP- $\beta$ homologous factor CHOP is induced by cell damage and exacerbates ER stress by poorly defined mechanisms that may include a reversal of the translation block that characterizes the initial ER stress response [86, 87]. CHOP knockout prolongs beta cell survival during ER stress [88].

ERK1/2 activity suppresses CHOP transcription [89]. The CHOP gene promoter contains a sequence similar to the region of the insulin gene that binds MafA. MafA binds to the CHOP promoter in cells exposed to normal physiological glucose concentrations [89]. Binding of MafA to the CHOP gene is decreased by inhibition of ERK1/2 activity and MafA binding suppresses CHOP promoter activity in reconstitution assays. Inhibition of ERK1/2 activity increases expression of CHOP protein, consistent with the idea that MafA suppresses CHOP transcription in beta cells. Thus, ERK1/2 regulate the expression of genes both positively and negatively that are important for beta cell function.

\section{Acknowledgments}

We thank current and past members of the Cobb laboratory and many colleagues for helpful comments and Dionne Ware for administrative assistance. This work was supported by grants DK34128 and DK55310 from the National Institutes of Health and grant I1243 from the Welch foundation. MCL was supported by an American Diabetes Association mentor-based postdoctoral fellowship during early stages of this work.

\section{References}

1 Roberts PJ, Der CJ. Targeting the Raf-MEK-ERK mitogenactivated protein kinase cascade for the treatment of cancer. Oncogene 2007; 26:3291-3310.

2 Lee JC, Kumar S, Griswold DE, Underwood DC, Votta BJ, Adams JL. Inhibition of p38 MAP kinase as a therapeutic strategy. Immunopharmacology 2000; 47:185-201.

3 Hirosumi J, Tuncman G, Chang L, et al. A central role for JNK in obesity and insulin resistance. Nature 2002; 420:333-336.

4 Lewis TS, Shapiro PS, Ahn NG. Signal transduction through MAP kinase cascades. Adv Cancer Res 1998; 74:49-139.

5 Raman M, Chen W, Cobb MH. Differential regulation of MAPKs. Oncogene 2007; 26:3100-3112.

6 Kyriakis JM, Avruch J. Mammalian mitogen-activated protein kinase signal transduction pathways activated by stress and inflammation. Physiol Rev 2001; 81:807-869.

7 Johnson GL, Lapadat R. Mitogen-activated protein kinase pathways mediated by ERK, JNK, and p38 protein kinases. Science 2002; 298:1911-1912.

8 Yoon S, Seger R. The extracellular signal-regulated kinase: Multiple substrates regulate diverse cellular functions. Growth Factors 2006; 24:21-44.

9 Gille H, Kortenjann M, Thomae O, et al. ERK phosphorylation potentiates Elk-1-mediated ternary complex formation and transactivation. EMBO J 1995; 14:951-962.

10 Levenson JM, O'Riordan KJ, Brown KD, Trinh MA, Molfese DL, Sweatt JD. Regulation of histone acetylation during memory formation in the hippocampus. J Biol Chem 2004; 279:4054540559.

11 Khoo S, Griffen SC, Xia Y, Baer R, German MS, Cobb MH. Regulation of insulin gene transcription by extracellular-signal regulated protein kinases (ERK) 1 and 2 in pancreatic beta cells. $J$ Biol Chem 2003; 278:32969-32977.

12 Maekawa M, Yamamoto T, Tanoue T, Yuasa Y, Chisaka O, Nishida E. Requirement of the MAP kinase signaling pathways for mouse preimplantation development. Development 2005; 132:1773-1783.

13 Saba-El-Leil MK, Vella FD, Vernay B, et al. An essential function of the mitogen-activated protein kinase Erk2 in mouse trophoblast development. EMBO Rep 2003; 4:964-968.

14 Rodriguez-Viciana $\mathrm{P}$, Tetsu O, Tidyman WE, et al. Germline mutations in genes within the MAPK pathway cause cardiofacio-cutaneous syndrome. Science 2006; 311:1287-1290.

15 Vojtek AB, Hollenberg SM, Cooper JA. Mammalian Ras interacts directly with the serine/threonine kinase Raf. Cell 1993; 74:205214.

16 Kyriakis JM, App H, Zhang XF, et al. Raf-1 activates MAP kinase-kinase. Nature 1992; 358:417-421.

17 Land H, Parada LF, Weinberg RA. Cellular oncogenes and multistep carcinogenesis. Science 1983; 222:771-778.

18 White MA, Nicolette C, Minden A, et al. Multiple Ras functions 
can contribute to mammalian cell transformation. Cell 1995; 80:533-541.

19 Zuber J, Tchernitsa OI, Hinzmann B, et al. A genome-wide survey of RAS transformation targets. Nat Genet 2000; 24:144-152.

20 Mansour SJ, Matten WT, Hermann AS, et al. Transformation of mammalian cells by constitutively active MAP kinase kinase. Science 1994; 265:966-970.

21 Ward y, Wang W, Woodhouse E, Linnoila I, Liotta L, Kelly K. Signal pathways which promote invasion and metastasis: critical and distinct contributions of extracellular signal-regulated kinase and Ral-specific guanine exchange factor pathways. Mol Cell Biol 2001; 21:5958-5969.

22 Zebisch A, Czernilofsky AP, Keri G, Smigelskaite J, Sill H, Troppmair J. Signaling through RAS-RAF-MEK-ERK: from basics to bedside. Curr Med Chem 2007; 14:601-623.

23 Glading A, Bodnar RJ, Reynolds IJ, et al. Epidermal growth factor activates m-calpain (calpain II), at least in part, by extracellular signal-regulated kinase-mediated phosphorylation. Mol Cell Biol 2004; 24:2499-2512.

24 McCawley LJ, Li S, Wattenberg EV, Hudson LG. Sustained activation of the mitogen-activated protein kinase pathway. A mechanism underlying receptor tyrosine kinase specificity for matrix metalloproteinase-9 induction and cell migration. $J$ Biol Chem 1999; 274:4347-4353.

25 Lee JC, Laydon JT, Mcdonnell PC, et al. A protein kinase involved in the regulation of inflammatory cytokine biosynthesis. Nature 1994; 372:739-746.

26 Hibi M, Lin A, Smeal T, Minden A, Karin M. Identification of an oncoprotein- and UV-responsive protein kinase that binds and potentiates the c-Jun activation domain. Genes Dev 1993; 7:2135-2148.

27 Lee YH, Giraud J, Davis RJ, White MF. c-Jun N-terminal kinase (JNK) mediates feedback inhibition of the insulin signaling cascade. J Biol Chem 2003; 278:2896-2902.

28 Morrison DK, Davis RJ. Regulation of MAP kinase signaling modules by scaffold proteins in mammals. Annu Rev Cell Dev Biol 2003; 19:91-118.

29 Choi K-Y, Satterberg B, Lyons DM, Elion EA. Ste5 tethers multiple protein kinases in the MAP kinase cascade required for mating in S. cerevisiae. Cell 1994; 78:499-512.

30 Marcus S, Polverino A, Barr M, Wigler M. Complexes between STE5 and components of the pheromone-responsive MAPKmodule. Proc Natl Acad Sci USA 1994; 91:7762-7766.

31 Mahanty SK, Wang Y, Farley FW, Elion EA. Nuclear shuttling of yeast scaffold Ste5 is required for its recruitment to the plasma membrane and activation of the mating MAPK cascade. Cell 1999; 98:501-512.

32 Bhattacharyya RP, Remenyi A, Good MC, Bashor CJ, Falick AM, Lim WA. The Ste5 scaffold allosterically modulates signaling output of the yeast mating pathway. Science 2006; 311:822826.

33 Yang SH, Yates PR, Whitmarsh AJ, Davis RJ, Sharrocks AD. The Elk-1 ETS-domain transcription factor contains a mitogenactivated protein kinase targeting motif. Mol Cell Biol 1998; 18:710-720.

34 Jacobs D, Glossip D, Xing H, Muslin AJ, Kornfeld K. Multiple docking sites on substrate proteins form a modular system that mediates recognition by ERK MAP kinase. Genes Dev 1999; 13:163-175.
35 Tanoue T, Adachi M, Moriguchi T, Nishida E. A conserved docking motif in MAP kinases common to substrates, activators and regulators. Nat Cell Biol 2000; 2:110-116.

36 Sharrocks AD, Yang SH, Galanis A. Docking domains and substrate-specificity determination for MAP kinases. Trends Biochem Sci 2000; 25:448-453.

$37 \mathrm{Xu}$ B, Wilsbacher JL, Collisson T, Cobb MH. The N-terminal ERK binding site of MEK1 is required for efficient feedback phosphorylation by ERK2 in vitro and ERK activation in vivo. J Biol Chem 1999; 274:34029-34035.

38 Seidel JJ, Graves BJ. An ERK2 docking site in the Pointed domain distinguishes a subset of ETS transcription factors. Genes Dev 2002; 16:127-137.

39 Chang CI, Xu B, Akella R, Cobb MH, Goldsmith EJ. Crystal structures of MAP kinase p38 complexed to the docking sites on its nuclear substrate MEF2A and activator MKK3b. Mol Cell 2002; 9:1241-1249.

40 Zhou T, Sun L, Humphreys J, Goldsmith EJ. Docking interactions induce exposure of activation loop in the MAP kinase ERK2. Structure 2006; 14:1011-1019.

41 Dimitri CA, Dowdle W, MacKeigan JP, Blenis J, Murphy LO. Spatially separate docking sites on ERK2 regulate distinct signaling events in vivo. Curr Biol 2005; 15:1319-1324.

$42 \mathrm{Xu}$ B, Stippec S, Robinson FL, Cobb MH. Hydrophobic as well as charged residues in both MEK1 and ERK2 are important for their proper docking. J Biol Chem 2001; 276:26509-26515.

43 Smith JA, Poteet-Smith CE, Malarkey K, Sturgill TW. Identification of an extracellular signal-regulated kinase (ERK) docking site in ribosomal S6 kinase, a sequence critical for activation by ERK in vivo. J Biol Chem 1999; 274:2893-2898.

44 Roux PP, Richards SA, Blenis J. Phosphorylation of p90 ribosomal S6 kinase (RSK) regulates extracellular signal-regulated kinase docking and RSK activity. Mol Cell Biol 2003; 23:47964804 .

45 Arvind R, Shimamoto H, Momose F, Amagasa T, Omura K, Tsuchida N. A mutation in the common docking domain of ERK2 in a human cancer cell line, which was associated with its constitutive phosphorylation. Int J Oncol 2005; 27:1499-1504.

46 Yazicioglu MN, Goad D, Ranganathan A, Whitehurst AW, Goldsmith EJ, Cobb MH. Mutations in ERK2 binding sites affect nuclear entry. J Biol Chem 2007; 282:28759-28767.

47 Pearson GW, Cobb MH. Cell condition-dependent regulation of ERK5 by cAMP. J Biol Chem 2002; 277:48094-48098.

48 Pearson GW, Earnest S, Cobb MH. Cyclic AMP selectively uncouples MAP kinase cascades from activating signals. Mol Cell Biol 2006; 26:3039-3047.

49 Xie L, Law BK, Chytil AM, Brown KA, Aakre ME, Moses HL. Activation of the Erk pathway is required for TGF-beta1-induced EMT in vitro. Neoplasia 2004; 6:603-610.

50 Ross KR, Corey DA, Dunn JM, Kelley TJ. SMAD3 expression is regulated by mitogen-activated protein kinase kinase-1 in epithelial and smooth muscle cells. Cell Signal 2007; 19:923-931.

51 Yamaguchi T, Wallace DP, Magenheimer BS, Hempson SJ, Grantham JJ, Calvet JP. Calcium restriction allows cAMP activation of the B-Raf/ERK pathway, switching cells to a cAMPdependent growth-stimulated phenotype. J Biol Chem 2004; 279:40419-40430

52 Omori S, Hida M, Fujita H, et al. Extracellular signal-regulated kinase inhibition slows disease progression in mice with poly- 
cystic kidney disease. J Am Soc Nephrol 2006; 17:1604-1614.

53 Schneider L, Clement CA, Teilmann SC, et al. PDGFRalphaalpha signaling is regulated through the primary cilium in fibroblasts. Curr Biol 2005; 15:1861-1866.

54 Joly D, Ishibe S, Nickel C, Yu Z, Somlo S, Cantley LG. The polycystin 1-C-terminal fragment stimulates ERK-dependent spreading of renal epithelial cells. J Biol Chem 2006; 281:2632926339.

55 Inglis PN, Boroevich KA, Leroux MR. Piecing together a ciliome. Trends Genet 2006; 22:491-500.

56 Yamaguchi T, Nagao S, Wallace DP, et al. Cyclic AMP activates B-Raf and ERK in cyst epithelial cells from autosomal-dominant polycystic kidneys. Kidney Int 2003; 63:1983-1994.

57 Chen R-H, Sarnecki C, Blenis J. Nuclear localization and regulation of erk- and rsk-encoded protein kinases. Mol Cell Biol 1992; 12:915-927.

58 Whitehurst AW, Cobb MH, White MA. Stimulus-coupled spatial restriction of extracellular signal-regulated kinase $1 / 2$ activity contributes to the specificity of signal-response pathways. $\mathrm{Mol}$ Cell Biol 2004; 24:10145-10150.

59 Liu P, Ying Y, Anderson RG. Platelet-derived growth factor activates mitogen-activated protein kinase in isolated caveolae. Proc Natl Acad Sci USA 1997; 94:13666-13670.

60 Reszka AA, Seger R, Diltz CD, Krebs EG, Fischer EH. Association of mitogen-activated protein kinase with the microtubule cytoskeleton. Proc Natl Acad Sci USA 1995; 92:8881-8885.

61 Drechsel DN, Hyman AA, Cobb MH, Kirschner MW. Modulation of the dynamic instability of tubulin assembly by the microtubuleassociated protein tau. Mol Biol Cell 1992; 3:1141-1154.

62 Gotoh Y, Nishida E, Matsuda S, et al. In vitro effects on microtubule dynamics of purified Xenopus M phase-activated MAP kinase. Nature 1991; 349:251-254.

63 Robinson MJ, Stippec SA, Goldsmith E, White MA, Cobb MH. Constitutively active ERK2 MAP kinase is sufficient for neurite outgrowth and cell transformation when targeted to the nucleus. Curr Biol 1998; 8:1141-1150.

64 Cheng M, Boulton TG, Cobb MH. ERK3 is a constitutively nuclear protein kinase. J Biol Chem 1996; 271:8951-8958.

65 Menice CB, Hulvershorn J, Adam LP, Wang CA, Morgan KG. Calponin and mitogen-activated protein kinase signaling in differentiated vascular smooth muscle. J Biol Chem 1997; 272:25157-25161.

66 Condorelli G, Vigliotta G, Iavarone C, et al. PED/PEA-15 gene controls glucose transport and is overexpressed in type 2 diabetes mellitus. EMBO J 1998; 17:3858-3866.

67 Tsukamoto T, Yoo J, Hwang SI, et al. Expression of MAT1/PEA15 mRNA isoforms during physiological and neoplastic changes in the mouse mammary gland. Cancer Lett 2000; 149:105113.

68 Nakopoulou L, Mylona E, Rafailidis P, Alexandrou P, Giannopoulou I, Keramopoulos A. Effect of different ERK2 protein localizations on prognosis of patients with invasive breast carcinoma. APMIS 2005; 113:693-701.

69 Casar B, Sanz-Moreno V, Yazicioglu MN, et al. Mxi2 promotes stimulus-independent ERK nuclear entry. EMBO J 2006; 26:635646.

70 Danziger N, Yokoyama M, Jay T, Cordier J, Glowinski J, Chneiweiss H. Cellular expression, developmental regulation, and phylogenic conservation of PEA-15, the astrocytic major phosphoprotein and protein kinase C substrate. J Neurochem 1995; 64:1016-1025.

71 Vigliotta G, Miele C, Santopietro S, et al. Overexpression of the ped/pea-15 gene causes diabetes by impairing glucose-stimulated insulin secretion in addition to insulin action. Mol Cell Biol 2004; 24:5005-5015.

72 Formstecher E, Ramos JW, Fauquet M, et al. PEA-15 mediates cytoplasmic sequestration of ERK MAP kinase. Dev Cell 2001; 1:239-250.

73 Whitehurst AW, Robinson FL, Moore MS, Cobb MH. The death effector domain protein PEA-15 prevents nuclear entry of ERK2 by inhibiting required interactions. J Biol Chem 2004; 279:1284012847.

74 Frödin M, Sekine N, Roche E, et al. Glucose, other secretagogues, and nerve growth factor stimulate mitogen-activated protein kinase in the insulin-secreting $\beta$-cell line, INS-1. J Biol Chem 1995; 270:7882-7889.

75 Khoo S, Cobb MH. Activation of MAP kinase by glucose is not required for insulin secretion. Proc Natl Acad Sci USA 1997; 94:5599-5604.

76 Benes C, Roisin MP, Van Tan H, Creuzet C, Miyazaki J, Fagard $\mathrm{R}$. Rapid activation and nuclear translocation of mitogen-activated protein kinases in response to physiological concentration of glucose in the MIN6 pancreatic beta cell line. J Biol Chem 1998; 273:15507-15513.

77 Arnette D, Gibson TB, Lawrence MC, et al. Regulation of ERK1 and ERK2 by glucose and peptide hormones in pancreatic beta cells. J Biol Chem 2003; 278:32517-32525.

78 Gibson TB, Lawrence MC, Gibson C, et al. Inhibition of glucosestimulated activation of extracellular signal-regulated protein kinases (ERK) 1 and 2 by epinephrine in pancreatic $\beta$ cells. Diabetes 2006; 55:1066-1073.

79 Gomez E, Pritchard C, Herbert TP. cAMP dependent protein kinase and $\mathrm{Ca}++$ influx through L-type voltage gated calcium channels mediate Raf independent activation of extracellular regulated kinase in response to glucagon like peptide-1 in pancreatic beta-cells. J Biol Chem 2002; 277:48146-48151.

80 Lawrence MC, McGlynn K, Park BH, Cobb MH. ERK1/2- dependent activation of transcription factors required for acute and chronic effects of glucose on the insulin gene promoter. $J$ Biol Chem 2005; 280:26751-26759.

81 German M, Ashcroft S, Docherty K, et al. The insulin gene promoter. Diabetes 1995;44:1002-1004.

82 Malecki MT. Genetics of type 2 diabetes mellitus. Diabetes Res Clin Pract 2005; 68 Suppl 1:S10-S21

83 Sharma A, Olson LK, Robertson RP, Stein R. The reduction of insulin gene transcription in HIT-T15 beta cells chronically exposed to high glucose concentration is associated with the loss of RIPE3b1 and STF-1 transcription factor expression. $\mathrm{Mol}$ Endocrinol 1995; 9:1127-1134.

$84 \mathrm{Lu}$ M, Seufert J, Habener JF. Pancreatic beta-cell-specific repression of insulin gene transcription by CCAAT/enhancer-binding protein beta. Inhibitory interactions with basic helix-loop-helix transcription factor E47. J Biol Chem 1997; 272:28349-28359.

85 Harding HP, Ron D. Endoplasmic reticulum stress and the development of diabetes: a review. Diabetes 2002; 51 Suppl 3: S455-S461

86 Oyadomari S, Araki E, Mori M. Endoplasmic reticulum stressmediated apoptosis in pancreatic beta-cells. Apoptosis 2002; 


\section{7:335-345.}

87 Marciniak SJ, Yun CY, Oyadomari S, et al. CHOP induces death by promoting protein synthesis and oxidation in the stressed endoplasmic reticulum. Genes Dev 2004; 18:3066-3077.

88 Oyadomari S, Koizumi A, Takeda K, et al. Targeted disruption of the Chop gene delays endoplasmic reticulum stress-mediated diabetes. J Clin Invest 2002; 109:525-532.

89 Lawrence MC, McGlynn K, Naziruddin B, Levy MF, Cobb MH. Differential regulation of CHOP-10/GADD153 gene expression by MAPK signaling in pancreatic beta cells. Proc Natl Acad Sci USA 2007; 104:11518-11525. 